\title{
Best tigecycline dosing for treatment of infections caused by multidrug-resistant pathogens in critically ill patients with different body weights
}

This article was published in the following Dove Press journal:

Drug Design, Development and Therapy

\author{
Mohamed M Ibrahim' \\ Abdulla M Abuelmatty ${ }^{2}$ \\ Gehan H Mohamed ${ }^{3}$ \\ Mohsen A Nasr ${ }^{4}$ \\ Amal K Hussein ${ }^{5}$ \\ Mohy El Deen Ebaed ${ }^{6}$ \\ Hatem A Sarhan ${ }^{5}$ \\ 'Department of Clinical Pharmacy, \\ Faculty of Pharmacy, Minia University, \\ Minia, Egypt; ${ }^{2}$ Department of \\ Pharmacy, Jahra Hospital, Jahra, \\ Kuwait; ${ }^{3}$ Department of Internal \\ Medicine, Faculty of Medicine, Cairo \\ University, Cairo, Egypt; ${ }^{4}$ Department \\ of Internal Medicine, Faculty of \\ Medicine, Ain Shams University, Cairo, \\ Egypt; ${ }^{5}$ Department of Pharmaceutics, \\ Faculty of Pharmacy, Minia University, \\ Minia, Egypt; ${ }^{6}$ Department of \\ Biochemistry, Egyptian Ministry of \\ Interior, Cairo, Egypt
}

Background: The intensive care unit (ICU) is a center of multidrug-resistant (MDR) pathogens. This is due to overuse of antibiotics in the treatment of critically ill patients. Tigecycline is a broad-spectrum antibiotic that belongs to the glycylcycline group. Tigecycline has been indicated in treatment of complicated intra-abdominal infections (cIAIs) and complicated skin and soft-tissue infections (cSSTIs).

Objective: This study was done to discover the best dose regimen of tigecycline in treatment of cSSTIs and cIAIs, especially in patients who are critically ill and obese, for clinical outcomes and safety.

Setting: The study was conducted in an adult ICU that consists of 25 beds in a general hospital and was conducted within 2 years. A total of 954 patients were screened in this study.

Methods: This was a retrospective cohort study that compared the clinical outcomes of patients: mortality, ICU stay, and safety of using two different dose regimens of tigecycline between patients with different body weight who were treated for infections caused by MDR pathogens in the ICU. The study was conducted within 2 years. All results were collected from patients' files and were analyzed with SPSS version 20.

Main outcome: The study was implemented to figure out the best dose regimen of tigecycline to achieve a reduction in mortality, ICU stay, treatment duration, and secondary septic-shock incidence with minimum side effects in treatment of cSSTIs and cIAIs in patients with different body weight.

Results: There was a significant improvement in mortality, ICU stay, recurrent infection by the same organism, duration of tigecycline treatment, number of patients who had first negative culture after starting treatment, secondary bacteremia, and secondary septic shock with patients who used high-dose regimens of tigecycline in different subgroups of body weight, with no significant difference in side effects.

Conclusion: The use of high-dose tigecycline resulted in a significant enhancement in all clinical outcomes, especially mortality and ICU stay when used in treatment of overweight and obese patients with cSSTIs and cIAIs.

Keywords: tigecycline, obese patients, intensive care unit, complicated intra-abdominal infections, complicated skin and soft-tissue infections

\section{Introduction}

Treatment of nosocomial infection and hospital-acquired bacterial infections is becoming the biggest challenge for health-care professionals, due to the continuous increase in prevalence of multidrug-resistant (MDR) bacteria like methicillin-resistant Staphylococcus aureus, vancomycin-resistant Enterococcus spp., Acinetobacter baumannii, 
Klebsiella pneumoniae, carbapenemase-producing Enterobacteriaceae, and extended-spectrum $\beta$-lactamase-producing Enterobacteriaceae. MDR organisms increase morbidity, mortality, duration of hospitalization, and medical costs. ${ }^{1}$ Any delay in starting appropriate antimicrobial therapy is most likely to raise morbidity and mortality among infected patients, and inadequate therapy has been known to be accompanied by overblown mortality and increased length of hospitalization. ${ }^{2}$ A huge rate of resistance is found to wellknown antimicrobial agents, such as $\beta$-lactams (penicillin, cephalosporins, and carbapenems), glycopeptides, aminoglycosides, and fluoroquinolones, which may reduce the effectiveness of such drugs, ${ }^{3}$ so we need to investigate the safety and efficacy of new antimicrobial molecules, such as tigecycline.

The first new molecule in the glycylcycline-antibiotic class is tigecycline, which has excellent activity on a wide range of bacteria: aerobic or anaerobic and also MDR. ${ }^{4,5}$ Tigecycline has been approved by the US Food and Drug Administration (FDA) and the European Medicines Agency for the treatment of complicated intra-abdominal infections (cIAIs) and complicated skin and soft-tissue infections (cSSTIs). ${ }^{6,7}$ The FDA also recently approved it for the treatment of community-acquired pneumonia. ${ }^{8}$ We conducted a retrospective study to investigate the best dose regimen of tigecycline in treatment of patients infected by MDR pathogens, such as methicillin-resistant $S$. aureus, extendedspectrum $\beta$-lactamase, Acinetobacter, and others.

\section{Methods}

\section{Study design and participants}

This was a retrospective cohort study conducted in an adult intensive care unit (ICU) between 2013 and 2014. This ICU consists of 14 medical beds that receive patients from medical wards and 11 surgical beds that receive patients from surgical wards, and it is located in a tertiary hospital that has about 1,000 beds. A total of 1,430 patients were admitted within the period of the study: 696 patients in 2013 and 734 in 2014. Based on inclusion criteria, only 68 patients were enrolled. These patients were classified into four subgroups based on body weight by body-mass index (BMI; Figure 1): underweight, BMI $<18.5 \mathrm{~kg} / \mathrm{m}^{2}$; normal weight, BMI 18.5-24.9 kg/m²; overweight BMI $25-29.9 \mathrm{~kg} / \mathrm{m}^{2}$; and obese, BMI $30-34.9 \mathrm{~kg} / \mathrm{m}^{2}{ }^{9}{ }^{9}$ All results were collected retrospectively from patients' medical files and analyzed statistically to figure out which dose was suitable for each subgroup of patients. In this study, we used the Kolmogorov-Smirnov test to value variable distributions.
Data with abnormal distribution were assessed with the Mann-Whitney $U$ test, data with normal distribution with Student's $t$-test, and categorical variables with $\chi^{2}$ or Fisher's exact test. There were very few missing data, and our method for handling these was pairwise deletion, ${ }^{10}$ because they were missing at random. ${ }^{11}$

\section{Antimicrobial agent}

This study estimated the microbiological and clinical outcomes of different dosing regimens of one of the most powerful broad-spectrum antibiotics that we have in our hospital to treat MDR Gram-negative (except Pseudomonas) and Gram-positive pathogen. It is a tigecycline molecule that we use in the treatment of SSTIs, IAIs, and community-acquired pneumonia. We excluded patients who had any hepatic problems, because tigecycline is usually used with caution for these patients: loading dose $100 \mathrm{mg}$, then maintenance dose $25 \mathrm{mg}$ twice daily. Tigecycline was given in 2013 as per its normal dose regimen of $100 \mathrm{mg}$ loading dose, then $50 \mathrm{mg}$ every 12 hours, which is recommended by the FDA, ${ }^{12}$ but the high-dose regimen - 100 mg every 12 hours - was given based on the recommendation of our antibiotic committee to overcome MDR Gram-negative bacteria.

\section{Ethics approval}

As this was a retrospective cohort study, formal consent from the patients was not required, because all patient data collected came from their medical files without any interference in treatment plans. The ethics committee of Minia University judged that this study did not require ethical approval or patient consent. Patient confidentiality has been maintained, and all patient data were anonymized.

\section{Study-entry criteria}

Inclusion criteria were: patients with microorganisms treated by tigecycline, with documented culture; those with pathogens that were susceptible to tigecycline in SSTIs, IAIs, and community-acquired infections; and those who had been on tigecycline treatment $>3$ days. Patients received tigecycline alone as single therapy, were admitted to the adult ICU, and were aged $\geq 13$ years. Exclusion criteria were: patients receiving tigecycline combined with other antibiotics; those who had not completed $\geq 3$ days on tigecycline; those with microorganisms not treated with tigecycline; those using tigecycline in non-FDA-indicated diseases, such as ventilatorassociated pneumonia; and those with any hepatic problems at the start of the study. 


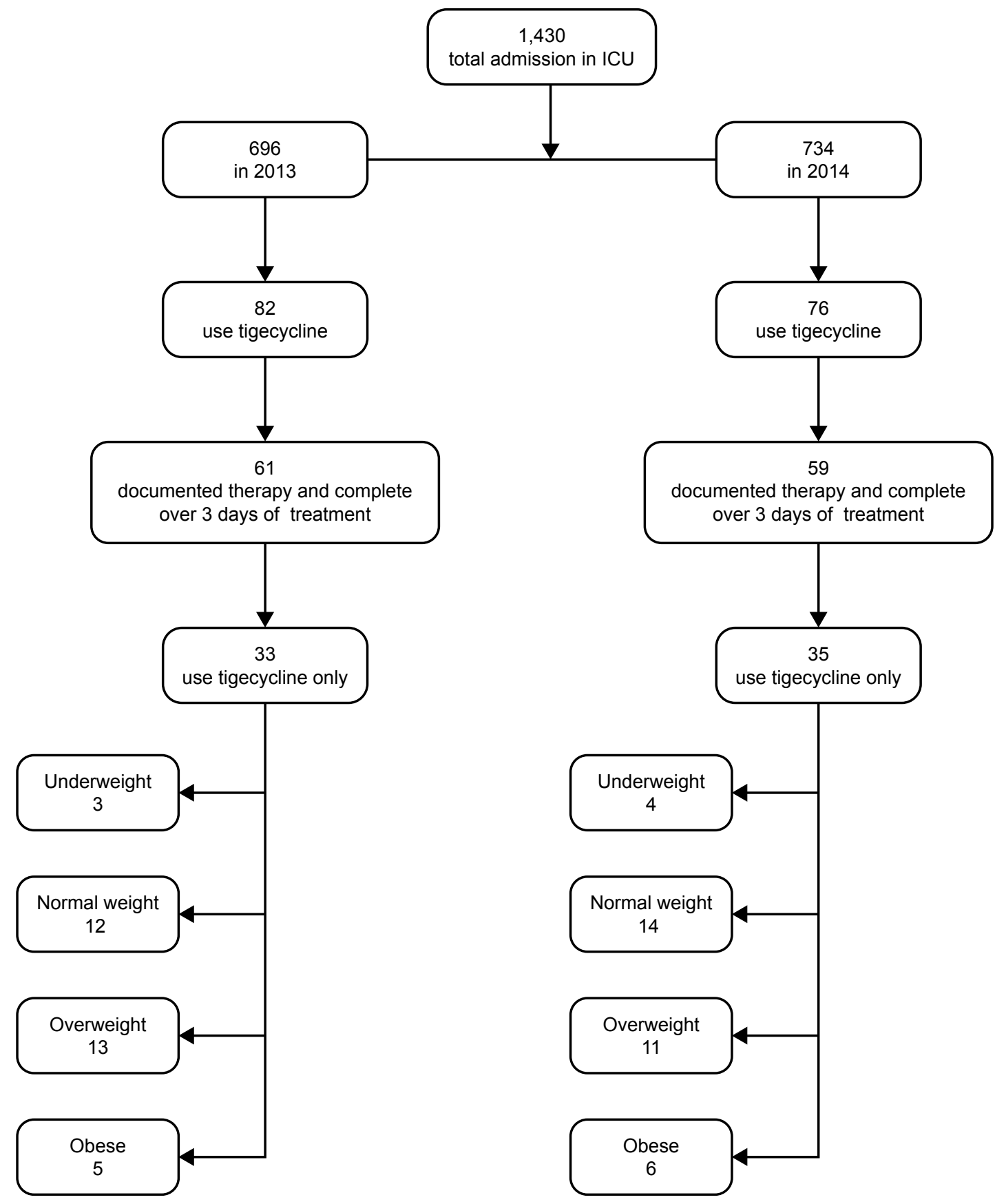

Figure I Distribution chart for study-inclusion process by year of study. Abbreviation: ICU, intensive care unit.

\section{Results}

Finally, results were gathered from 33 patients who received the normal dose in 2013 and 35 who received the high dose in 2014, as shown in Figure 1. It was uncovered that the most common site of infection was SST in all subgroups, as shown in Tables 1 and 2. The most associated frequent comorbidity in all subgroups was cardiovascular disorders, diabetes disorders, renal impairment disorders, and hematological disorders with averages of $89 \%, 78 \%, 51 \%$, and $26 \%$, respectively. Average baseline sepsis-related organ-failure assessment (SOFA) and systemic inflammatory response syndrome (SIRS) scores were almost the same in all subgroups in the 2 years of the study: 9.5 and 3.4, respectively, as shown in Tables 3 and 4.

The most prevalent organism in all subgroups was Acinetobacter, with average $41 \%$ prevalence, as shown in 
Table I Sites of infection in underweight and normal-weight subgroups

\begin{tabular}{|l|l|l|l|l|}
\hline & $\mathbf{2 0 I 3}$ & $\mathbf{2 0 I 4}$ & $\mathbf{2 0 I 3}$ & $\mathbf{2 0 I 4}$ \\
\cline { 2 - 5 } & $\begin{array}{l}\text { Underweight, } \\
\mathbf{n}=\mathbf{3}\end{array}$ & $\begin{array}{l}\text { Underweight, } \\
\mathbf{n}=\mathbf{4}\end{array}$ & $\begin{array}{l}\text { Normal } \\
\text { weight, } \\
\mathbf{n = 1 2}\end{array}$ & $\begin{array}{l}\text { Normal } \\
\text { weight, } \\
\mathbf{n}=1 \mathbf{4}\end{array}$ \\
\hline clAls & $\mathrm{I}(33)$ & $\mathrm{I}(25)$ & $4(33)$ & $6(42)$ \\
\hline cSSTls & $2(67)$ & $3(75)$ & $8(67)$ & $7(50)$ \\
\hline CAP & 0 & 0 & $\mathrm{I}(8)$ & $2(14)$ \\
\hline
\end{tabular}

Note: Data presented as n (\%).

Abbreviations: clAls, complicated intra-abdominal infections; cSSTls, skin and soft-tissue infections; CAP, community-acquired pneumonia.

Tables 5 and 6 . The average age was 57.5 years, and almost half the patients were female (51\%). Ethnicity was mainly Middle Eastern ( $>65 \%)$, as shown in Tables 7 and 8.

The most exciting clinical outcome was in the overweight subgroup, where mortality on the normal-dose regimen was $38 \%$, but with high-dose regimen was $9 \%$ $(P<0.01)$. Treatment duration with the normal dose was $17.34 \pm 2.98$ days, but with the high dose was $6.19 \pm 1.05$ days with $P$-value (0.01). ICU hospital stay with the normal dose was $29.65 \pm 4.76$ days, but with the high dose was $12.02 \pm 2.11$ days $(P=0.01)$. Patients who had negative results from the next culture on the normal dose comprised $31 \%$, but on the high dose $73 \%(P=0.02)$. Patients who had septic shock on the normal dose comprised $23 \%$, but on the high dose this was $9 \%(P=0.03)$. Patients who had secondary bacterial infection with the same first organism on the normal dose comprised $8 \%$, but 0 on the high dose $(P<0.01)$, as shown in Table 10.

Results were similar in the obese subgroup, where mortality on the normal dose was $40 \%$, while on the high dose it was $0(P<0.01)$. Treatment duration with the normal dose was $17.98 \pm 3.75$ days and with the high dose $6.01 \pm 0.55$ days $(P=0.02)$. ICU stay on the normal dose was $30.98 \pm 3.05$ days and with the high dose $13.55 \pm 2.65$ days $(P=0.01)$. Patients with negative results from the first culture after treatment initiation comprised $40 \%$ in the regular-dose subgroups,

Table 2 Sites of infection in overweight and obese subgroups

\begin{tabular}{|c|c|c|c|c|}
\hline & 2013 & 2014 & 2013 & 2014 \\
\hline & $\begin{array}{l}\text { Overweight, } \\
n=13\end{array}$ & $\begin{array}{l}\text { Overweight, } \\
\mathrm{n}=\mathrm{II}\end{array}$ & $\begin{array}{l}\text { Obese, } \\
n=5\end{array}$ & $\begin{array}{l}\text { Obese, } \\
n=6\end{array}$ \\
\hline clAls & $7(54)$ & $5(45)$ & $2(40)$ & $3(50)$ \\
\hline cSSTIs & $5(38)$ & $6(54)$ & $2(40)$ & $3(50)$ \\
\hline CAP & I (7) & 0 & I (20) & I (I7) \\
\hline
\end{tabular}

Note: Data presented as $\mathrm{n}(\%)$.

Abbreviations: clAls, complicated intra-abdominal infections; cSSTIs, skin and soft-tissue infections; CAP, community-acquired pneumonia. while with the high dose this was $83 \%(P=0.02)$. Patients who had septic shock with the normal dose comprised $20 \%$, but with the high dose this was $0(P<0.01)$. Patients who had secondary bacterial infections with the same first organism with normal dose comprised $20 \%$, but with the high dose this was $0(P<0.01)$, as shown in Table 10. Also, with the underweight and normal-weight subgroups, improvement in clinical outcomes on the high-dose regimen was significant in mortality, ICU stay, percentage of patients cured by the first culture, secondary septic shock, and secondary bacterial infection, as shown in Table 9.

All subgroups had almost the same associated side effects: nausea, vomiting, and diarrhea. Nearly all patients in the different subgroups had the same low incidence of skin, hepatic, renal, and hematological side effects. Not even one patient had another infection with another organism within the treatment period. Only one patient in normal-weight subgroup was stopped from continuing the treatment, because of vomiting with high dose regimen, as shown in Tables 11 and 12.

\section{Discussion}

All results were collected during 2013-2014, after which comparison was done between the results collected to assess which dose regimen would be effective in different bodyweight subgroups. After statistical analysis, it was found that there were significant differences among all subgroups in mortality, whereas patients who received high-dose tigecycline had a low mortality rate compared with patients who received normal doses. There were also significant differences among all subgroups in tigecycline duration of treatment and ICU stay, where the duration of tigecycline treatment and ICU stay was less in patients receiving high doses than those receiving normal doses.

Moreover, significant differences among almost all subgroups in number of patients who had direct negative first culture after starting therapy, secondary septic shock, and secondary bacterial infection with the same microorganism, while the number of patients who had negative results in the first culture after starting therapy was higher with the high-dose regimen, but fewer patients had secondary septic shock and secondary bacterial infection with the same organism with the high-dose regimen. All results were found to be in agreement with those of de Pascale et al at a teaching hospital in Rome, where he tried to conduct a retrospective study of prospectively collected data in the ICU and found that tigecycline was well tolerated at a higher-thanstandard dose in a cohort of critically ill patients with severe infections. ${ }^{13}$ 
Table 3 Comorbidities associated with infection and SOFA and SIRS scores in underweight and normal-weight subgroups

\begin{tabular}{|c|c|c|c|c|}
\hline & 2013 & 2014 & 2013 & 2014 \\
\hline & Underweight, $n=3$ & Underweight, $n=4$ & Normal weight, $n=12$ & Normal weight, $n=14$ \\
\hline CVD & $3(100)$ & $3(75)$ & $9(75)$ & $12(86)$ \\
\hline CNS & 0 & 0 & $\mathrm{I}(8)$ & $2(14)$ \\
\hline Oncology & 0 & I (25) & 0 & 0 \\
\hline Hematology & $1(33)$ & I (25) & $4(33)$ & $3(2 I)$ \\
\hline Hepatic & 0 & 0 & 0 & 0 \\
\hline Renal & $2(67)$ & $2(50)$ & $6(50)$ & $7(50)$ \\
\hline Diabetes & $2(67)$ & $3(75)$ & $8(67)$ & $10(71)$ \\
\hline Neutropenic patients & 0 & I (25) & 0 & 0 \\
\hline \multicolumn{5}{|l|}{ Baseline scores } \\
\hline SOFA & $8.5 \pm I . I$ & $9.1 \pm 1.2$ & $9.1 \pm I .1$ & $9.5 \pm 0.9$ \\
\hline SIRS & $3.1 \pm 0.1$ & $3.25 \pm 0.3$ & $3.4 \pm 0.3$ & $3.34 \pm 0.22$ \\
\hline
\end{tabular}

Note: Data presented as $\mathrm{n}(\%)$ or mean $\pm \mathrm{SD}$.

Abbreviations: CNS, central nervous system; CVD, cardiovascular disorder; SIRS, systemic inflammatory response syndrome; SOFA, sepsis-related organ-failure assessment.

Table 4 Comorbidities associated with infection and SOFA and SIRS scores for overweight and obese subgroups

\begin{tabular}{|c|c|c|c|c|}
\hline & 2013 & 2014 & 2013 & 2014 \\
\hline & Overweight, $n=13$ & Overweight, n=I I & Obese, $n=5$ & Obese, $n=6$ \\
\hline CVD & II (85) & $10(91)$ & $5(100)$ & $6(100)$ \\
\hline CNS & $2(15)$ & $3(27)$ & I (20) & $I(17)$ \\
\hline Oncology & $I(8)$ & I (9) & 0 & $\mathrm{I}(\mathrm{I7})$ \\
\hline Hematology & $2(15)$ & $3(27)$ & I (20) & $2(33)$ \\
\hline Hepatic & 0 & 0 & 0 & 0 \\
\hline Renal & $6(46)$ & $6(55)$ & $2(40)$ & $3(50)$ \\
\hline Diabetes & $10(77)$ & $9(82)$ & $5(100)$ & $5(83)$ \\
\hline Neutropenic patients & 0 & I (9) & 0 & 0 \\
\hline \multicolumn{5}{|l|}{ Baseline scores } \\
\hline SOFA & $9.9 \pm 1.5$ & $10.1 \pm 1.4$ & $9.7 \pm 1.3$ & $10.2 \pm 1.6$ \\
\hline SIRS & $3.5 \pm 0.3$ & $3.8 \pm 0.2$ & $3.2 \pm 0.2$ & $3.6 \pm 0.4$ \\
\hline
\end{tabular}

Note: Data presented as $n(\%)$ or mean \pm SD.

Abbreviations: CNS, central nervous system; CVD, cardiovascular disorder; SIRS, systemic inflammatory response syndrome; SOFA, sepsis-related organ-failure assessment.

Table 5 Organism prevalence in underweight and normal-weight subgroups

\begin{tabular}{|c|c|c|c|c|}
\hline & 2013 & 2014 & 2013 & 2014 \\
\hline & Underweight, $n=3$ & Underweight, $n=4$ & Normal weight, $n=12$ & Normal weight, $n=14$ \\
\hline \multicolumn{5}{|l|}{$\mathrm{Gram}^{-}$prevalence } \\
\hline Acinetobacter & $2(67)$ & $2(50)$ & $3(25)$ & $5(36)$ \\
\hline Klebsiella & 0 & 0 & $2(17)$ & $2(14)$ \\
\hline Escherichia coli & 0 & 0 & $3(25)$ & $3(2 I)$ \\
\hline Enterobacter & 0 & I (25) & $\mathrm{I}(8)$ & I (7) \\
\hline \multicolumn{5}{|l|}{$\mathrm{Gram}^{+}$prevalence } \\
\hline Enterococcus & $\mathrm{I}(33)$ & 0 & $\mathrm{I}(8)$ & $\mathrm{I}(7)$ \\
\hline Staphylococcus (MRSA) & 0 & $\mathrm{I}(25)$ & I (8) & $\mathrm{I}(7)$ \\
\hline Streptococcus spp. & 0 & 0 & I (8) & I (7) \\
\hline
\end{tabular}

Note: Data presented as $n$ (\%).

Abbreviation: MRSA, methicillin-resistant S. aureus. 
Table 6 Organism prevalence in overweight and obese subgroups

\begin{tabular}{|c|c|c|c|c|}
\hline & 2013 & 2014 & 2013 & 2014 \\
\hline & Overweight, $n=13$ & Overweight, n=I I & Obese, $n=5$ & Obese, $n=6$ \\
\hline \multicolumn{5}{|l|}{$\mathrm{Gram}^{-}$prevalence } \\
\hline Acinetobacter & $4(3 I)$ & $5(45)$ & $2(40)$ & $2(33)$ \\
\hline Klebsiella & $2(15)$ & I (9) & I (20) & $\mathrm{I}(17)$ \\
\hline Escherichia coli & $3(23)$ & $3(27)$ & I (20) & $\mathrm{I}(\mathrm{I7})$ \\
\hline Enterobacter & I (8) & 0 & 0 & 0 \\
\hline \multicolumn{5}{|l|}{$\mathrm{Gram}^{+}$prevalence } \\
\hline Enterococcus & $I(8)$ & 0 & 0 & 0 \\
\hline Staphylococcus (MRSA) & I (8) & $2(18)$ & I (20) & $2(33)$ \\
\hline Streptococcus spp. & I (8) & 0 & $\mathrm{I}(20)$ & 0 \\
\hline
\end{tabular}

Note: Data presented as $n$ (\%).

Abbreviation: MRSA, methicillin-resistant S. aureus.

On the other hand, patients who were treated with the high-dose regimen had more nausea and vomiting, strongly noticed within underweight and normal-weight patients, but no significant differences were noticed with other side effects like hepatic and renal function, infection with another organism, or hematological/dermatological side effects. Only one patient was dropped out of the study in the normalweight subgroup with the high-dose regimen because of side effects. This meant that the two dose regimens of tigecycline had the same safety profile. These results strongly agree with those observed by Ramirez et al, who found higher efficacy with tigecycline $100 \mathrm{mg}$ twice daily relative to lower doses of tigecycline and imipenem-cilastatin in the treatment of hospital-acquired pneumonia. The safety profile of the higher doses of tigecycline was similar to the known safety profile of the approved dose of tigecycline. ${ }^{14}$

All subgroups had the same duration of ICU stay before getting an infection, as well as the same duration between receiving culture results and starting therapy. No subgroup showed a significant difference in baseline SOFA or SIRS scores, which showed that all patients in the four subgroups had the same illness status before starting tigecycline treatment. Also, age, ethnicity, sex, comorbidities, organism prevalence, and site of infection were almost the same in all groups and with insignificant differences, which showed that nearly all patients had the same status before starting tigecycline treatment. Based on these results, clinicians have to consider high-dose tigecycline in MDR pathogen-infection treatment, especially when patients have a high BMI.

\section{Limitations}

Firstly, this was a retrospective, single-center study with a medium number of patients. Secondly, few patients were treated with tigecycline alone as monotherapy. This has an impact on research conclusions. Furthermore, we were not able to perform tissue-level or pharmacokinetic testing due to financial issues.

Table 7 Demographic data for underweight and normal-weight subgroups

\begin{tabular}{|c|c|c|c|c|c|c|}
\hline & 2013 & 2014 & \multirow[t]{2}{*}{$P$-value } & 2013 & 2014 & \multirow[t]{2}{*}{$P$-value } \\
\hline & Underweight, $n=3$ & Underweight, $n=4$ & & Normal weight, $n=12$ & Normal weight, $n=14$ & \\
\hline Age (years) & $51.9 \pm 9.7$ & $53.5 \pm 10.3$ & 0.83 & $57.4 \pm 9.9$ & $60.1 \pm 10.2$ & 0.71 \\
\hline Sex (female) & I (33) & $2(50)$ & 0.38 & $5(42)$ & $7(50)$ & 0.69 \\
\hline Baseline BMI $\left(\mathrm{kg} / \mathrm{m}^{2}\right)$ & $17.11 \pm 0.74$ & $|7.03 \pm 0.5|$ & 0.89 & $21.98 \pm 1.13$ & $20.7 I \pm I .76$ & 0.84 \\
\hline \multicolumn{7}{|l|}{ Ethnicity } \\
\hline Middle East & $2(67)$ & $3(75)$ & 0.39 & $8(67)$ & $10(7 I)$ & 0.85 \\
\hline Asian & I (33) & I (25) & 0.53 & $3(25)$ & $4(29)$ & 0.76 \\
\hline Others & 0 & 0 & 0.99 & $\mathrm{I}(8)$ & 0 & $<0.01$ \\
\hline
\end{tabular}

Note: Data presented as $\mathrm{n}(\%)$ or mean \pm SD.

Abbreviation: BMI, body-mass index. 
Table 8 Demographic data for overweight and obese subgroups

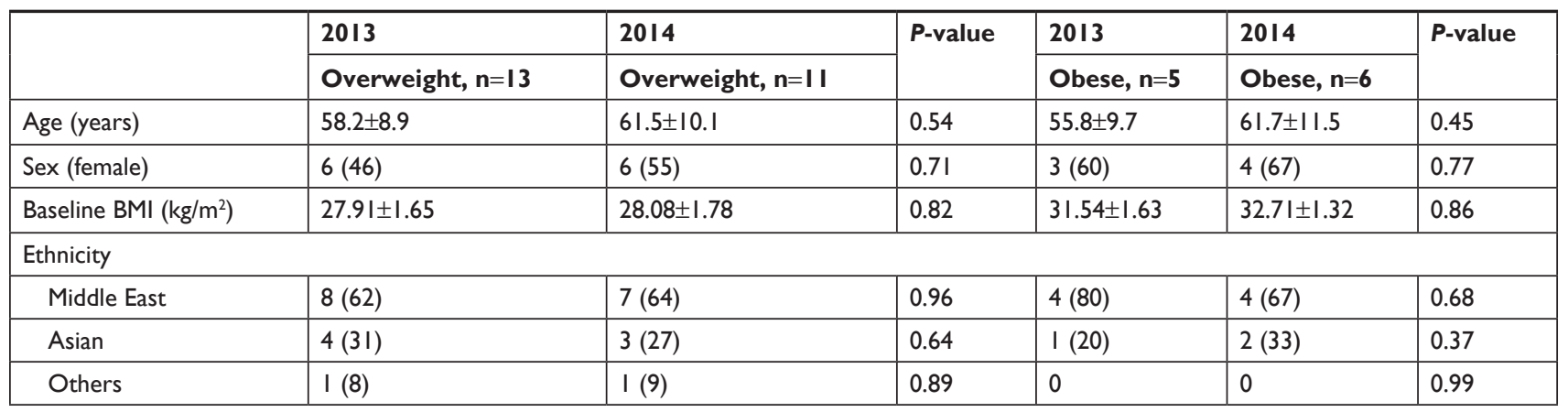

Note: Data presented as $n(\%)$ or mean \pm SD.

Abbreviation: BMI, body-mass index.

Table 9 Clinical outcomes for underweight and normal-weight subgroups

\begin{tabular}{|c|c|c|c|c|c|c|}
\hline & 2013 & 2014 & $P$-value & 2013 & 2014 & $P$-value \\
\hline & $\begin{array}{l}\text { Underweight, } \\
n=3\end{array}$ & $\begin{array}{l}\text { Underweight, } \\
n=4\end{array}$ & & $\begin{array}{l}\text { Normal weight, } \\
n=12\end{array}$ & $\begin{array}{l}\text { Normal weight, } \\
n=14\end{array}$ & \\
\hline Mortality & I (33) & 0 & $<0.01$ & $4(33)$ & $2(14)$ & 0.02 \\
\hline Tigecycline treatment (days) & $14.2 \pm 0.7$ & $6.15 \pm 0.85$ & 0.01 & $16.66 \pm 1.1$ & $7.99 \pm 1.12$ & 0.01 \\
\hline ICU stay (days) & $25.84 \pm 3.77$ & $11.84 \pm 2.89$ & 0.01 & $26.02 \pm 3.19$ & $12.39 \pm 2.05$ & 0.01 \\
\hline $\begin{array}{l}\text { Patients with negative first culture } \\
\text { after starting therapy }\end{array}$ & I (34) & $3(75)$ & 0.01 & $4(33)$ & $10(7 \mid)$ & 0.02 \\
\hline Secondary septic shock & I (33) & 0 & $<0.01$ & $2(17)$ & $\mathrm{I}(7)$ & 0.04 \\
\hline $\begin{array}{l}\text { Secondary bacteremia with same } \\
\text { microorganism }\end{array}$ & 0 & 0 & 0.99 & I (8) & 0 & $<0.01$ \\
\hline ICU period before infection (days) & $5.75 \pm 2.1$ & $6.23 \pm 2.22$ & 0.88 & $5.98 \pm 1.96$ & $5.43 \pm 2.34$ & 0.75 \\
\hline $\begin{array}{l}\text { Time between receiving culture } \\
\text { result and starting therapy (hours) }\end{array}$ & $3.80 \pm 1.5$ & $4.1 \pm 1.34$ & 0.78 & $3.55 \pm 0.98$ & $3.6 \pm 0.75$ & 0.74 \\
\hline
\end{tabular}

Note: Data presented as $n$ (\%).

Abbreviation: ICU, intensive care unit.

Table 10 Clinical outcomes for overweight and obese subgroups

\begin{tabular}{|c|c|c|c|c|c|c|}
\hline & 2013 & 2014 & $P$-value & 2013 & 2014 & $P$-value \\
\hline & $\begin{array}{l}\text { Overweight, } \\
n=13\end{array}$ & $\begin{array}{l}\text { Overweight, } \\
n=11\end{array}$ & & $\begin{array}{l}\text { Obese, } \\
n=5\end{array}$ & $\begin{array}{l}\text { Obese, } \\
n=6\end{array}$ & \\
\hline Mortality & $5(38)$ & I (9) & $<0.01$ & $2(40)$ & 0 & $<0.01$ \\
\hline Tigecycline treatment (days) & $17.34 \pm 2.98$ & $6.19 \pm 1.05$ & 0.01 & $17.98 \pm 3.75$ & $6.01 \pm 0.55$ & 0.02 \\
\hline ICU stay (days) & $29.65 \pm 4.76$ & $12.02 \pm 2.11$ & 0.01 & $30.98 \pm 3.05$ & $13.55 \pm 2.65$ & 0.01 \\
\hline Patients with negative first culture after starting therapy & $4(3 I)$ & $8(73)$ & 0.02 & $2(40)$ & $5(83)$ & 0.02 \\
\hline Secondary septic shock & $3(23)$ & I (9) & 0.03 & I (20) & 0 & $<0.01$ \\
\hline Secondary bacteremia with same microorganism & I (8) & 0 & $<0.01$ & I (20) & 0 & $<0.01$ \\
\hline ICU period before infection (days) & $6.21 \pm 1.65$ & $5.88 \pm 2.01$ & 0.78 & $6.36 \pm 2.51$ & $6.46 \pm 2.08$ & 0.84 \\
\hline $\begin{array}{l}\text { Time between receiving culture result and starting } \\
\text { therapy (hours) }\end{array}$ & $3.31 \pm 0.52$ & $3.12 \pm 0.82$ & 0.88 & $3.22 \pm 0.64$ & $3.49 \pm 0.69$ & 0.83 \\
\hline
\end{tabular}

Note: Data represented as $n$ (\%).

Abbreviation: ICU, intensive care unit. 
Table I I Side effects associated with underweight and normal-weight subgroups

\begin{tabular}{|c|c|c|c|c|}
\hline \multirow[t]{2}{*}{ After starting therapy } & 2013 & 2014 & 2013 & 2014 \\
\hline & Underweight, $n=3$ & Underweight, $n=4$ & Normal weight, $n=12$ & Normal weight, $n=14$ \\
\hline Nausea & I (33) & $2(50)$ & $2(17)$ & $4(29)$ \\
\hline Vomiting & 0 & I (25) & I (8) & $4(29)$ \\
\hline Diarrhea & 0 & 0 & 0 & I (7) \\
\hline Hepatic problems & 0 & 0 & I (8) & 0 \\
\hline Renal problem & 0 & 0 & 0 & 0 \\
\hline Skin problems & 0 & I (25) & I & 0 \\
\hline Infection with another microorganism & 0 & 0 & 0 & 0 \\
\hline Hematological problem & 0 & 0 & $2(17)$ & I (7) \\
\hline Dropped out because of side effect & 0 & 0 & 0 & I (7) \\
\hline
\end{tabular}

Note: Data represented as $\mathrm{n}(\%)$.

Table 12 Side effects associated with overweight and obese subgroups

\begin{tabular}{|c|c|c|c|c|}
\hline \multirow[t]{2}{*}{ After starting therapy } & 2013 & 2014 & 2013 & 2014 \\
\hline & Overweight, $n=13$ & Overweight, $\mathrm{n}=\mathrm{I}$ I & Obese, $n=5$ & Obese, $n=6$ \\
\hline Nausea & $2(15)$ & $2(18)$ & $\mathrm{I}(20)$ & I (I7) \\
\hline Vomiting & $2(15)$ & $2(18)$ & I (20) & $\mathrm{I}(\mathrm{I})$ \\
\hline Diarrhea & 0 & I (9) & 0 & 0 \\
\hline Hepatic problems & $I(8)$ & I (9) & 0 & 0 \\
\hline Renal problem & 0 & 0 & 0 & 0 \\
\hline Skin problems & 0 & 0 & 0 & 0 \\
\hline Infection with another microorganism & 0 & 0 & 0 & 0 \\
\hline Hematological problem & I (8) & I (9) & 0 & 0 \\
\hline Dropped out because of side effect & 0 & 0 & 0 & 0 \\
\hline
\end{tabular}

Note: Data presented as n (\%).

\section{Conclusion}

Tigecycline use in this study improved clinical outcomes and mortality and reduced ICU stay significantly in obese patients.

\section{Disclosure}

The authors report no conflicts of interest in this work.

\section{References}

1. Siegel JD, Rhinehart E, Jackson M, Chiarello L; Healthcare Infection Control Practices Advisory Committee. Management of multidrugresistant organisms in health care settings, 2006. Am J Infect Control. 2007;35(10 Suppl 2):S165-S193.

2. Hyle EP, Lipworth AD, Zaoutis TE, Nachamkin I, Bilker WB, Lautenbach E. Impact of inadequate initial antimicrobial therapy on mortality in infections due to extended-spectrum beta-lactamase-producing enterobacteriaceae: variability by site of infection. Arch Intern Med. 2005;165(12):1375-1380.

3. Ventola CL. The antibiotic resistance crisis: part 1: causes and threats. P T. 2015;40(4):277-283.

4. Bratu S, Tolaney P, Karumudi U, et al. Carbapenemase-producing Klebsiella pneumoniae in Brooklyn, NY: molecular epidemiology and in vitro activity of polymyxin B and other agents. $J$ Antimicrob Chemother. 2005;56(1):128-132.

5. Hawkey P, Finch R. Tigecycline: in-vitro performance as a predictor of clinical efficacy. Clin Microbiol Infect. 2007;13(4):354-362.
6. Babinchak T, Ellis-Grosse E, Dartois N, et al; Tigecycline 301 Study Group; Tigecycline 306 Study Group. The efficacy and safety of tigecycline for the treatment of complicated intra-abdominal infections: analysis of pooled clinical trial data. Clin Infect Dis. 2005;41(Suppl 5):S354-S367.

7. Ellis-Grosse EJ, Babinchak T, Dartois N, et al; Tigecycline 300 cSSSI Study Group; Tigecycline 305 cSSSI Study Group. The efficacy and safety of tigecycline in the treatment of skin and skin-structure infections: results of 2 double-blind phase 3 comparison studies with vancomycin-aztreonam. Clin Infect Dis. 2005;41(Suppl 5):S341-S353.

8. Tanaseanu C, Milutinovic S, Calistru PI, et al; 313 Study Group. Efficacy and safety of tigecycline versus levofloxacin for communityacquired pneumonia. BMC Pulm Med. 2009;9:44.

9. Douketis JD, Paradis G, Keller H, Martineau C. Canadian guidelines for body weight classification in adults: application in clinical practice to screen for overweight and obesity and to assess disease risk. CMAJ. 2005;172(8):995-998.

10. Kim JO, Curry J. The treatment of missing data in multivariate analysis. Sociol Methods Res. 1977;6(2):215-240.

11. Rubin DB. Inference and missing data. Biometrika. 1976;63(3):581-592.

12. TYGACIL ${ }^{\circledR}$ (tigecycline) [prescribing information]. Philadelphia, PA: Wyeth Pharmaceuticals Inc.; 2010.

13. De Pascale G, Montini L, Pennisi M, et al. High dose tigecycline in critically ill patients with severe infections due to multidrug-resistant bacteria. Crit Care. 2014;18(3):R90.

14. Ramirez J, Dartois N, Gandjini H, Yan JL, Korth-Bradley J, McGovern PC. Randomized phase 2 trial to evaluate the clinical efficacy of two highdosage tigecycline regimens versus imipenem-cilastatin for treatment of hospital-acquired pneumonia. Antimicrob Agents Chemother. 2013; 57(4):1756-1762. 


\section{Publish your work in this journal}

Drug Design, Development and Therapy is an international, peerreviewed open-access journal that spans the spectrum of drug design and development through to clinical applications. Clinical outcomes, patient safety, and programs for the development and effective, safe, and sustained use of medicines are the features of the journal, which has also been accepted for indexing on PubMed Central. The manuscript management system is completely online and includes a very quick and fair peer-review system, which is all easy to use. Visit http://www.dovepress.com/testimonials.php to read real quotes from published authors.

Submit your manuscript here: http://www.dovepress.com/drug-design-development-and-therapy-journal 